\title{
In memory of Miriam Greenfield
}

In November 2021, the sad news reached the editors of Science in Context that Miriam Greenfield, our beloved managing editor for over twenty years, had passed away.

An unfailingly warm, open and kind individual, with a remarkable ability to take joy in the simplest of things, Miriam was truly the bedrock of our journal production. She was meticulous, committed, and her editing performed miracles with some of the texts submitted to our journal. Most importantly, her work was informed by her love of language and literature, as well as her keen curiosity and interest in the journal's contents. As she still recalled to us enthusiastically when she retired this spring, the first issue she accompanied upon joining the journal in 1999 was issue 12/4, which was devoted to the work and context of the philosopher Ernst Cassirer. "What a start to work on one of my favorite thinkers!" she wrote in her farewell to one of our editors, "And it continued to be a pleasure. I feel very lucky to have enjoyed my work here."

As she took pride in her work and in the quality of the publication she represented, we are proud to have been able to profit from Miriam's help for so many years. And as she found joy in her collaboration with the journal's many authors and her fellow editors, we will always remember, with fondness, the pleasure of working with her.

Leo Corry

Michael Elazar

Moritz Epple

Gideon Freudenthal

Snait Gissis

Asaf Goldschmidt

Boaz Hagin

Orna Harari

Alexandre Métraux

Jürgen Renn

Thom Rofé

Yosef Schwartz 